\title{
Assessing the educational value of one-to-one devices: have we been asking the right questions?
}

\author{
Marte Blikstad-Balas ${ }^{{ }^{*}}$ and Chris Davies ${ }^{\mathrm{b}}$ \\ University of Oslo ${ }^{a}$; University of Oxford ${ }^{b}$
}

The provision for every pupil in schools of 1:1 digital devices such as tablets and laptops is claimed to offer a range of benefits, both practical and educational. Opinions are still divided as to whether the benefits for teaching and learning in fact outweigh the cost, disruption to established teaching practice, and distraction for learners. This paper presents studies carried out in three different settings where such schemes have been implemented, in order to consider the extent to which the benefits as presented in the research literature are working out in reality, and whether such benefits constitute an adequate argument in support of investing further in these technologies. The paper finds that there is considerable evidence of practical benefit for processes of teaching and learning from the availability in schools of 1:1 devices, but limited evidence of concerted or systematic strategies on the part of schools for helping young people to engage profitably and wisely with the digital world, with respect both to their learning and their wider lives.

Keywords: digital devices; digital literacy; schools; classroom technologies; tablets; iPads

\section{Introduction}

1:1 technologies - personal digital devices provided to individual students for use in schools and colleges - have been part of the school landscape since the early 2000s at least, in the form of laptops, notebooks and tablet computers. Although Larry Cuban dismissed the notion' back in 2006, questioning the "outlandish claims of technology champions that giving each student a laptop will revolutionize teaching and learning", a number of studies during the first decade of the century did indicate specific benefits: "Research suggests that [1:1] programs result in improved student writing, increased student engagement, improved information literacy and, in many cases, higher student test scores" (Warschauer and Ames, 2010:35). The ongoing development of portable Internet-connected devices since that time has resulted in fact in a steady expansion of 1:1 projects - initiatives warmly supported, not surprisingly, by the technology industry. In the constant search for the most suitable device, successive new iterations of the concept have been promoted as the best prospect in terms of low cost, small size, usability and Internet connectivity; none more so than the iPad which, following its launch in 2010 , promised to offer all those qualities and more, with its post-tech functionality, its apps, and its Steve Jobs pedigree.

Since that time, Chromebooks, Android tablets and hybrid tablet/laptops such as the Microsoft Surface have also become popular choices, but the iPad nonetheless has dominated the market for, and the discourse about, 1:1 devices in schools during the last five years or so. For that reason, iPads figure heavily here, but not necessarily as more worthy of attention than the other devices discussed. The present paper does not attempt to judge between any of these, but rather focuses on the general issue of the value or otherwise of enabling universal access to personal Internet-connected devices in the classroom. 
In doing so, we consider both published research and findings from our own case studies of the experiences of introducing and working with different kinds of 1:1 device within varied school contexts. Such research - including our own - has tended to be largely exploratory, trying to understand what is emerging in practice from these new opportunities for using digital technologies in classrooms, and seeking evidence of the ways in which they enhance processes of teaching and learning. In those respects, our specific purposes here are (i) to describe and illustrate the perspectives and assumptions surrounding 1:1 technologies that have come to dominate their evaluation and deployment in schools over recent years, and (ii) to probe the conceptions of educational value that arise from these.

\section{The growth in 1:1 technologies in school-based education}

According to a report from the British Educational Suppliers Association (BESA), conducted in June 2015, "71 per cent of primary and 76 per cent of secondary schools (an increase from 56 percent in 2014 in both school types) are making use of tablets in the classroom." BESA's report estimated " 721,000 tablets for use by pupils in classrooms across UK maintained schools and academies", suggesting that by the end of 2016 this number will have increased to over 946,000 . "This upward trend appears to be continuing with 15 per cent of schools suggesting that they will have $1: 1$ access to tablet technology by 2016 and 44 per cent of schools having one tablet per child by 2020" (BESA 2015).

The situation is very similar in developed economies globally with a number of countries already well advanced down this particular road (Jahnke \& Kumar 2014; Mango 2015; Ditzler 2016; Ifenthaler \& Schweinbenz 2016) and, as a report from Tablets for Schools pointed out in 2013, "Emerging economies in Asia and Eastern Europe have also announced the adoption of Tablets in schools, including South Korea, India, Kazakhstan and Turkey. Trials have already begun to explore the benefits for children's learning through the use of Tablets in France, the Netherlands, Japan, Singapore and Australia." (Clarke et al. 2013: 8). The Tablets for Schools reports states confidently "that it is not a matter of if but when Tablets will be universally adopted as a learning device in schools" (ibid.: 8).

Whilst BESA's speculative figure of 15 per cent of UK schools in the process of providing or enabling 1:1 provision of tablets to all students might well be exaggerated, and despite some initiatives falling short of initial expectations (e.g. California, reported in next section), high stakes investments in various touchscreen technologies continue to be made in a number of technologically-committed schools, such as Shirelands Academy in the Midlands, that has bought Microsoft Surface 3 devices for all its students. Such a ground-breaking initiative displays an impressive commitment to technological innovation in ways that both offers the possibility of forging new possibilities for teaching and learningii, and testifies to a school's cutting edge credentials in a highly competitive educational marketplace:

... with contemporary society tasking educational curriculum and teachers to engage in the role of preparing young people for the escalating expectations and demands of the globalized workplace (Regelski, 2006), it is increasingly seeming futile to exclude these technological advances that youth were already embracing to connect on a global level ... Yet, it is not clear where the line of demarcation lies between what is educationally beneficial and what is simply a demonstration of allowing technology in the classroom, nor is it clear what constitutes a useful part of the learning process. (Peluso 2012: 25-26)

Peluso goes on to argue that determining "how and what technologies are educationally relevant is highly ambiguous and needs further in-depth research", a point made more 
recently by Ditzler, who suggests that the recent arrival of tablets requires fresh consideration by research of the effects of technology use in the classroom (2016: 183). She goes on to argue that ".. a review of websites and articles on 1:1 iPad initiatives indicated that 1:1 iPad programs focus on integration and best practices, rather than on clearly articulated educational goals" (Ditzler 2016:190).

From the early days of these devices in schools, published studies and evaluations of tablet implementation projects in schools have tended to characterise the educational benefits of iPads and similar devices in relation to a disparate but largely unchanging set of criteria (Heinrich 2012, Burden, K. et al. 2012; Clark,\& Luckin, 2013). In the initial stages, many such reports, in the absence of substantial longitudinal material evidence of specific educational benefit, also exhibited a level of positivity that tends to characterize the early stages of a promising educational innovation:

The iPads 'Have revolutionised teaching.' In the opinion of one Longfield teacher, a statement that, while not necessarily shared by all, sums up the views of most students and many staff. (Heinrich 2012: 14)

Heinrich summarises the outcomes of the Longfield evaluation as follows:
This study reviews the impact on learning and teaching of the introduction of iPad devices at Longfield Academy, Kent since September 2011. It finds that with the majority of pupils now having the devices, there has been a significant and very positive impact on learning, as well as significant and still developing changes in pedagogy. Students are very positive about the devices and the impact they have on their motivation, ability to research, communicate and collaborate, while staff increasingly exploit the range of educational Apps made available. While some technical issues have been identified, these are dealt with through excellent project management. The outcomes at Longfield clearly demonstrate the value of the iPad as an educational tool. (Heinrich 2012: 5)

This report also states that "Teachers have identified significant benefits for their workload and have also identified cost savings", "The quality and standard of pupil work and progress is rising" and "All find the iPad easy to use"(Heinrich 2012: 4), thus encompassing what constitutes a now well-established repertoire of the benefits cited in advocating the use of these devices, commonly featuring in studies of their implementation: high motivation, ease-of-use, transformation of pedagogy and learning, efficiency benefits.

In the following section, we explore the key elements of this repertoire in more depth, with reference to further studies published since the time of the Longfield study.

\section{Rationales for devices}

Since the first days of microcomputers in the early 1980s, there have been multiple and often conflicting rationales for advocating their incorporation into school education. Computers were perceived as tools to augment established pedagogical practices, to transform established pedagogical practices, to prepare young people for employment in a post-industrial economy, and as a means of nurturing future computer programmers (Selwyn, 2014: 183-4). Such rationales responded to a variety of political, economic and theoretical agendas, were often highly future oriented, and for the most part were based on limited evidence from practice. They seldom addressed the more immediate concerns of teachers, especially with regard to the question of whether the investment of time and 
resources required to maintain a cutting edge engagement with each new wave of digital technologies was entirely in their own or their students' best interests.

Despite relentless developments since that time in the nature of the technologies themselves, and the profound impact on how we engage with the world that has resulted from our uses of them, the arguments in support of their use in schools have evolved only slightly. Analysis of a range of studies of 1:1 device projects - primarily focusing on tablets, and especially the iPad, during the period in question - shows three main dimensions that typically structure discussion of their benefits for education:

1. Pedagogical change: ways in which $1: 1$ devices facilitate shifts towards more independent and active learning, and increase student motivation;

2. $21^{\text {st }}$ century learning: focus on skills for the future, such as collaboration and teamwork, digital communication skills, computer coding skills;

3. Logistical and economic: efficiencies afforded by these technologies for teachers and students individually and when interacting with one other; cost savings e.g. computer suites, textbooks, photocopying, ancillary staff.

\section{$\underline{\text { Pedagogical change }}$}

The most salient claims made for these technologies propose improvements in current classroom practices of teaching and learning. Clarke et al. emphasise that the introduction of tablet computers represents an opportunity to think innovatively about pedagogy:

it was felt to be essential that the devices should be introduced, or indeed integrated, alongside a model of teaching and learning which was adapted to prepare pupils for the future. The Tablet was merely a means to facilitate this. As one Assistant Head Teacher explained: [The introduction of Tablets was used] as a backdoor way to re-engage my staff with what good pedagogy is. (Clarke et al. 2013:28)

Others suggest that the inherent qualities and functionalities of the machine itself are themselves capable of driving such change:

As a relatively new portable computer format, the TPC [tablet personal computer] offers features with the potential to enhance learning and instruction in classroom settings .. From an instructional point of view, beneficial features of TPCs range from the availability of tools such as simulations, cameras, and microphones to e-books and interactive textbooks, smart learning networks, and instant feedback. Furthermore, its distinguishing features are high mobility, low proneness to software problems, and instant usability .. These characteristics can clearly contribute to student-centered learning and to a more differentiated form of instruction ... (Ifenthaler \& Schweinbenz 2016: 306)

Most are agreed, though, that such change occurs through a combination of machine affordances and teacher commitment to bringing about change. Ditzler et al. quote Glassett and Schrum (2009) to describe the use of this technology as "transforming learning routines, which includes accessing advanced learning resources and content, igniting cognitive processes that enhance learning (e.g., active inquiry vs. memorization), and changing teacher roles from delivery of content to facilitator or learning coach" (Ditzler et al. 2016: 206). 
At the same time, considerable emphasis is placed on the benefits to learning gained through increased student motivation. Such claims are particularly notable in evaluations published in the first years of the iPad's introduction:

Use of the iPad was focused mainly in the areas of numeracy and literacy which were identified as weaknesses in each school, and teachers identified several learning gains in these areas including increased enthusiasm by students, better understanding of complicated ideas which could be broken down into their constituent parts, and greater engagement and motivation in learning through applications which were games-based in nature. (Burden, K. et al. 2012: 27)

there is a clear consensus from all involved that the iPads are having a positive impact on both motivation and how students work. (Heinrich, P. 2012: 21)

\section{$\underline{21^{\text {st }} \text { century learning }}$}

Some reports take the notion of pedagogical change to a further stage, suggesting that it leads to the development of $21^{\text {st }}$ century skills that will prove vital to the future success of students, once out in the workplace:

the adoption of one-to-one Tablet use is best managed within the schools through a collective agreement on the principles of the pedagogical changes that are likely to be brought about. ... Preparing pupils for life and work in the 21st century is the common objective of these schools, and learning how to manage time and the possibility of distraction through one-to-one Tablet use is an important part of this preparation. (Clarke et al. 2013:2)

In terms of content, the key technology-related learning benefit is seen as relating to computer coding and computational thinking (the latter notion first proposed in 1980 by Seymour Papert in Mindstorms). The emphasis on learning to code has gained considerable attention globally, advocated for instance as a route for improving the prospects of young people in the developing world by teaching them how to code apps:

UNESCO and its partners strive to provide young people with the high-level skills and confidence to develop, promote, and sell locally relevant mobile apps that solve local issues of sustainable development and provide employment ${ }^{\mathrm{iii}}$.

The perspective from wealthier economies emphasises values of global competitiveness as much as inclusiveness and economic development:

... problem-solving, collaboration, communication and connection making - the critical computational practices all students need for the 21st century. Curriculum developers must offer software tools that enable students to engage in algorithmic thinking and create computational artifacts with tablets and other tools across all subjects. Policy makers must work to make sure computer science is part of the core of student learning, and not merely an elective. Together these forces can help create the context for students to genuinely become educated digital citizens $^{\text {iv }}$

The past decade has seen a strong focus in the United States on increasing the use of technology in the nation's schools, to spur innovation and foster global economic competitiveness.

(McKnight et al. 2016: 194)

Either way, the focus on coding constitutes a rare attempt to locate educational value in the nature of digital technologies themselves, rather than merely deploying them as learning tools to support study of the established curriculum. Further areas of potential importance 
for learning, such as the wider aspects of the cultural and social changes initiated by increased access to the Internet, gain little attention in any of implementation projects reviewed, although the National Curriculum for England, Wales and Northern Ireland does make passing mention of how the study of computing might enhance such perspectives:

Computing also ensures that pupils become digitally literate - able to use, and express themselves and develop their ideas through, information and communication technology - at a level suitable for the future workplace and as active participants in a digital world ${ }^{v}$.

\section{$\underline{\text { Logistical }}$}

The logistical benefits of 1:1 tablet technologies are reported in many studies as being very influential in schools' decisions to enter into implementation projects:

Several schools anticipate making cost savings over the coming years, and a few have already begun to make savings. Two schools are planning to discontinue IT suites in order to save money, while three schools reduced their number of suites and another three fully decommissioned all their IT suites at the same time as the Tablets were introduced. (Clarke et al. 2013: 41)

As projects progress, a greater range of economies become apparent, in terms of teacher productivity in particular (whereas the considerable costs of upgrading wi-fi across a school site, and other operational costs associated with tablet implementations such as apps and content management, somewhat negate the supposed cost savings in relation to not maintaining computer suites):

Teachers highlighted how technology provides efficiencies for educators and learners, making daily routines like checking and grading homework quicker and easier, which in turn helped teachers restructure their time to focus more on instructional planning and delivery." (Ditzler et al. 2016: 206)

Increasingly, also, efficiency benefits are being promoted for students as much as teachers:

With accessibility in mind, and based on direct feedback from educators and students, the Microsoft development teams continue to expand the capabilities and availability of the tools that help students of all abilities be successful. Many features previously exclusive to OneNote desktop are now coming to OneNote Online, Word desktop and Online, Office Lens, and beyond, to make sure more students have access to these tools. vi

\section{Positive versus negative perceptions}

In 2013, Clark and Luckin's report on what the research has to say about iPads in the classroom confidently states that:

For learners iPads are easy to use and attractive. The research on iPad use and adoption overwhelmingly reports that tablet devices have a positive impact on students' engagement with learning. Findings report increased motivation, enthusiasm, interest, engagement, independence and self-regulation, creativity and improved productivity. (Clark and Luckin 2013: 4)

As suggested above, many early evaluations of iPad implementations were predominantly positive, intent on identifying and pointing out a wide range of potential benefits for education, as reflected in Clark and Luckin's overview. Greater ambivalence about the benefits of these technologies has become evident more recently - particularly notable in 
this respect is the change of heart in Los Angeles schools where, following a massive initial investment in iPads the decision was made to remove 2,100 iPads from students, instead offering a wider range of devices such as Chromebooks:

"While nobody hated the iPad, by any means, the iPad was edged out by some key feedback," said Joel Handler, Hillsborough's director of technology. Students saw the iPad as a "fun" gaming environment, while the Chromebook was perceived as a place to "get to work." And as much as students liked to annotate and read on the iPad, the Chrome book's keyboard was a greater perk. (The Atlantic 2014)

The most commonly reported negative perceptions of these technologies tend to relate to issues such as parental disquiet over-reliance on technology, and student misuse at home and at school -

... a number of parents were concerned about traditional reading and writing skills, preferring to purchase text books rather than use the iPad as an e-reader. ... parents and students both reported concerns about off-task behaviours or the increased opportunity for distraction, particularly in the areas of gaming or social networking. (Willcocks and Redmond 2014: 403-4)

- and lack of commitment to or confidence in the use of the machines on the part of some teachers, resulting in irregular use, weak modeling of good uses to students by teachers, coupled with high levels of regulation over the ways in which the devices could be used -

Some teachers and students did not utilize the iPad efficiently or in a relevant manner. ...The direction that [a] teacher gave to students regarding the library use for selecting a book was followed by a statement, "You can use your iPad if that is what you really want." The classrooms in these cases did not use the iPad, leaving the device face down on the desk for the majority of the class session. (Ditzler et al. 2016: 185)

"The worst thing was that it was rarely used in school and the teachers did not do many lessons using it, which made me feel as if the Tablet was going to waste." Pupil, Greenford High School (Clarke et al. 2013:88)

How the teachers used the device was indicative of how the students would use it. For example, in one math class the teacher only used the device to upload and view homework assignments, and the students in the class did the same. During the observations the students had their iPads face down on their desks until the teacher asked them to look at the paper they needed to do for homework. (Ditzler et al. 2016: 185).

Reservations were also expressed about the sometimes low educational quality of many of the apps used on the tablets:

Many of the available apps, however, are focused on content acquisition rather than on increasing higher order thinking skills such as critical thinking and creative thinking. (Ditzler et al. 2016: 183)

\section{Summary}

The composite picture that emerges from such studies is of a useable and potentially useful - whilst not yet indispensable - tool that supports teaching, learning and the work of schools in disparate ways, without the emergence as yet of a definitive educational rationale that addresses the concerns articulated by Peluso and Ditzler, that such programmes implementing 1:1 devices should be primarily oriented towards educationally relevant goals. 
In the sections that follow, we explore these perspectives more closely by considering findings from three separate small-scale case studies of our own that explored how iPads and other 1:1 devices were being used in schools, and the views of students using them.

\section{Findings from exploratory case studies}

\section{Study designs}

In the course of the last four years, the authors visited a number of schools in the UK and Scandinavia (specifically in Norway and Denmark) where students have been given continuous access to 1:1 devices of various kinds in school, in various configurations (including a Bring Your Own Device project in a UK school, not discussed here). As indicated in the introduction to this paper, the focus of these studies was exploratory, asking questions of the following kind: how are these devices being used, what purposes are they serving, and in what ways are they proving beneficial?

The first two studies reported below were conducted by author 2 in the UK. The first was based in the lower school of a large comprehensive in southern England, where an implementation project had recently been started with the whole of year seven (i.e. eleven year olds in the first year of their secondary school career), in which all pupils had been provided by the school with an iPad mini. We were invited to conduct an exploratory study by the teacher responsible for the innovation, who was keen to gain feedback on the progress of the project, with a view to developing a systematic evaluation of learning improvements related to the iPad implementation.

The second study was based in a prominent independent school also in the south of England which over several previous years had displayed a commitment to technological innovation that was now being taken to a potentially higher level by the introduction of Microsoft Surface machines (tablet/laptop hybrids with stylus). The context of the study was similar to the one described above: informal and exploratory, but with a view to identifying the kinds of evidence that might demonstrate efficacy for learning.

In the case of both the above studies, a range of qualitative methods appropriate to the exploratory research questions were used. All evidence cited comes from a combination of lesson observations, interviews with students and with teachers, augmented in the case of the second study by an online survey of $50+$ older students.

The third study reported here was conducted by author 1 in Norway, growing out of a longer-term study focusing primarily on the literacy practices of 18 to19 year-old students in the three school subjects: religion and ethics, Norwegian language arts and history (Author $1,2012 ; 2013)$ and focuses on the use of 1:1 laptops.

\section{State secondary school, central England}

This comprehensive school initiated a scheme in the school year 2013/14 by which all year seven pupils (i.e. aged 11-12) were presented with an iPad mini, the long-term plan being that this device would be theirs to use and look after throughout the compulsory period of their schooling, until the end of year 11 (aged 16). The school paid the full cost of this initiative. Substantial preparation time was devoted to staff induction into the scheme, involving establishing clear agreed procedures and rules for the use of the machines in class and beyond, and exploring pedagogical applications. Students were expected to carry these 
devices (all of which had rubberized protective covers) with them at all times during school, to use them only on their teachers' instructions and guidance, and to take them home each evening.

According to the teacher in charge of the scheme, there was wide variation in terms of teacher buy-in to the scheme, with some unconvinced by the educational value of the enterprise, especially with respect to the cost and the potential disruption to established classroom practices, and others highly enthusiastic about exploring new possibilities for supporting teaching and learning in the classroom, and keen to experiment. It appears that the majority were agnostic but willing to work along with the project, and during the first two terms the majority of year seven students experienced regular use of the devices structured into their lessons right across the curriculum. The typical range of uses during the school day is represented by the following examples provided by different year 7 students:

- I take pictures of homework, if it is a long one

- we have this sort of coaching app, and if we get something in swimming wrong, you can watch it afterwards and get it right next time.

- sometimes we have to go on the internet and type in these things, like anagram generators in English.

- if you like need a dictionary in English - you just type the word in and it gives you a definition and other words you can use

- my spelling is not very good, and it's improved because it's always correcting the spelling mistakes I make

- we use it to research, or as a reading book. We use it as a thesaurus. Our teacher has learned how to mirror it now.

It is certainly the case that one of the most popular, and less anticipated, uses made of the iPads was of their camera for both still and video capture. As well as taking pictures of homework instructions on the board, students both chose and, as time went on, were encouraged, to film a wide range of activities, including physical movement in P.E., keyboard skills in music, examples of food cooked in home economics, and their own artwork. Over time, these images were used to augment portfolio evidence of performance in visual or physical activity.

The examples from the English subject area characterize the kinds of efforts made by teachers to find uses for Internet connectivity. Some use was made of the opportunity to read e-books during private reading time. Most notably, it was unheard-of for the iPads to be used for any kind of written work beyond occasional note-taking. The final comment above reflects the students' awareness of their teachers' own processes of learning and gaining confidence, and the comment below shows positive approval of the kind of shift in classroom culture that some teachers managed to bring about by having everyone working together with and through the tool:

- it's more fun, something we are all doing together, it makes everyone concentrate cos we are doing the same things together.

Observations of nine different lessons across the course of a single day by a team of five postgraduate research students in the course of the study revealed a fairly consistent picture of structured and directed use of the machines in class. The year 7 students were required to lift up their machines at the start of the lesson to show they had theirs with them, and then to put them face down on the desk until asked to use them. The tasks these students undertook were largely determined by the apps that had been selected for the 
lesson, which were of variable quality and relevance. The most positive learning experiences reported and observed showed how an appropriately selected app, when integrated skilfully into the flow of a lively classroom managed by a confident teacher, appeared to contribute significantly to the quality of the learning experience, without appearing to over-regulate the students' uses of their devices. The following is an extract of a report by one of the research student observers:

\begin{abstract}
"Projected on a board is an image of an application on Algebra that all of the students are to download for the class. He jovially directs the class 'You will have 5 minutes to download this maths app and we will begin'. Nick sits in the back of the classroom playing a DragonBallZGame. It appears he has already downloaded the app. [Mr S. says] '... I want all of you to watch on your own the intro video in the app, that gets the basic idea across.' A chaotic melody of unsynchronized videos starts playing throughout the class, some hold their iPads to their ears to hear. Mr S. seems to welcome the organic asynchronous progression of the class. "Once you finish the intro, start using the app." Nick has already begun blazing through the questions in the app. It is like an extension of the game he was playing earlier ... Nick is already on level three and asking Mr S. about solving equations with 2 variables. Mr S. applauds him in front of the whole class and then one-on-one directs him to more difficult problems."
\end{abstract}

Taken together, the observations by the research student team crystallise the impression gained over several months during the first year of the scheme, that it had successfully achieved many of its logistical goals, although without having markedly demonstrated the ambitious pedagogical goals intended by its managers (who were strongly committed to notions of transformation of teaching and learning). In the process of reviewing that first year, nineteen year 7 students, representing a spread of academic ability, were interviewed for this research in small groups in order to elicit their perceptions of the implementation of the scheme. Their opinions of the experience were positive, if largely low-key. None of those interviewed wished to lose possession of the machines, but nonetheless a degree of disappointment with the way they formed part of their classroom learning was evident:

- we used it more during the first term, and now we don't use it that much.

- I don't think all the teachers actually like using it ... I don't know why.

- I don't think we use them enough at school to make a big difference.

- it's useful, but it could be more useful.

The perception of these particular students of the benefits of the iPad minis away from school were even more low-key. Few reported substantial benefit from these particular school-provided machines for schoolwork at home, often because they already had adequate access to similar equipment at home:

- I rarely use my school iPad at home (don't want to damage it) - I use my phone, I go on the Xbox -

- I spend more time on my iPod than my iPad at home. It's probably BBM and Skype, and I play games.

- $\quad$ only if it requires research

- I never really download much things I like on this iPad, cos I have another at home. This is a school iPad.

- I prefer to use my android laptop because its got a touch screen. just generally not the biggest fan of the iPad, I prefer using my laptop. it's a lot nicer, faster internet, bigger storage.

- I generally use my computer. I find it easier, and there's generally restrictions [with the iPad]. I type, and I find it easier to navigate with the mouse. With the computer there's more space. 
- I might do some homework, some research on it. I might read a couple of books, not much. prefer to use a computer.

Although the project seemed to be advancing satisfactorily during its second year, with many teachers gaining in confidence and expertise in incorporating the devices in their teaching, it transpired that a change in the top management of the school had triggered serious questions about the wisdom of pursuing the scheme as originally planned, especially in the light of some complaints from parents about the uses their children made of the devices. Following a period of review, the project was discontinued before the end of the second year. It appears that the difficulty of being able to adduce compelling evidence of the impact in terms of measurable improvement in learning outcomes left those supporting the project with insufficient ammunition to counter the skepticism of some of their colleagues, as well as some parents and senior staff not directly involved in the project. The iPads were retrieved from the pupils before the end of the year, and re-constituted into classroom sets for use in the future by teachers on demand.

\section{Independent school, south east England}

This leading independent boarding school, with a well-established commitment to educational technology innovation, and outstanding resources, provided the opportunity to observe how the implementation of digital devices fares under highly propitious of circumstances. It had been the case for several years that all students were expected to carry some form of personal digital device with them at all times, which for the older students mainly took the form of laptops (a high proportion being MacBook Airs). The school's current move to Microsoft Surface tablets was made partly in order to enable the use of digital handwriting (especially for science and maths), and partly in order to get the most out of a shift to Microsoft OneNote as the school's content management system.

The focus of the study reported here was on sixth formers: senior students in the last two years of their education at the school and preparing for their final public examinations. In order to learn about how they made use of personal digital devices in the course of their formal learning, and how they felt about the innovations in digitally supported education that were currently taking place in the school, we were able to observe some teaching, conduct an online survey, and subsequently carry out a number of focus group interviews. The survey ( 52 respondents) collected both quantitative and qualitative data, asking students about their preferences for personal devices, and the specific uses to which they put these, and their feelings about the place of technology in their learning. The subsequent focus group interviews attempted to probe these topics in more depth with a smaller number (15) of students.

All the 52 students responding to the survey said they use their main personal device, either a laptop (nearly $80 \%$ ) or a Surface tablet (nearly $20 \%$ ), several times everyday, and normally carried a personal device with them at all times, although a few felt that there was too much pressure from the school to do so. Survey responses indicated a range of ways in which technology provision was valued. In response to the request in the survey to "describe some ways in which your teachers use technology particularly effectively in your lessons", the following main kinds of example were most often cited (synthesised from survey responses):

- $\quad$ sharing notes made in lessons via OneNote which can be accessed at all times

- distributing resources via OneNote

- distributing resources, sources \& links, documents prior to lesson, Powerpoints subsequent 
to lesson via email

- $\quad$ having work set online /sending \& receiving feedback on work/ writing essays and test drafts of essays in a format easily correctable by the teacher

- being provided with a wide range of online video material on topics being learnt/ talks about subject/ current affairs on news websites/ case studies/ presentations/ educational videos/ demonstration on the smart board

- encouragement to do own research on laptops and the Internet

- $\quad$ working collaboratively via OneNote and Google Docs

On the basis of the above, it was evident that the school provides a well-resourced and wellused set of systems for content delivery, digitally supported learning activities (such as collaborative note-taking and projects through Google docs), and lesson follow-up, primarily through OneNote. In addition, email is used a great deal, both to deliver material quickly and simply, and for communication especially between teachers and students regarding their work. Enabled to manage their own personal learning networks as they move round the school each day via their laptops, Surfaces and other devices, including smartphones, it would be hard to conceive of how the level of digital tool support to which these students had access throughout their studies both in and out of lessons could be substantially raised.

Not all students were unambiguously enthusiastic about this provision. Whilst in some respects some of the negative comments were nothing more than niggles about certain technological choices - such as disruptions arising from the move to OneNote from the previous intranet - some students also expressed misgivings about the extent to which they were supposed to use technology in their studies. When asked in the survey to comment on things "they did not particularly like" about how technology was used for learning in school, students mentioned a number of reservations (quoted verbatim):

- $\quad$ Prefer to have hand written revision on paper rather than on computer

- Laptops can be distracting as there are so many things you could be doing rather than work

- $\quad$ scruffy handwriting when writing on a surface [i.e. with electronic stylus]

- slideshows

- Requires laptop for every lesson

- $\quad$ sometimes unreliable

- causes some students to be distracted

- Lack of paper copies of work

- Lack of variety and disengaging sometimes

- Improper use of onenote - when it is easier to write out by hand than hand in electronically

- In Biology with Mr xxx, we use onenote, which I don't like, for every lesson so it has all of my notes however I prefer to use paper and a folder.

- $\quad$ Prefer paper

Some issues hinted at in the above comments also surfaced in the focus group discussions, almost all relating to what appears to be an underlying concern of many students: the need for them to balance the benefits of the digital practices that give them rapid and convenient access to a wide array of learning materials with the necessity to maintain the traditional "pen and paper" practices through which their final public assessments will be conducted. Many were concerned about the risk of dependence on keyboards undermining their ability to handwrite. Some experienced additional - and perhaps less rational - anxiety regarding the dependability of digital organization and storage of precious notes and learning 
materials:

Marianne. Yeah, I use paper. I actually rarely use my laptop. I don't really use it to take notes or I write notes. Because obviously our exams are written. And I just know for myself, if I get too used to doing it on my laptop, I wouldn't be ready for writing in the exam.

Not merely did the students feel the need to keep their handwriting skills alive but, as the above extract suggests and the following ones confirm, there was a widely-shared belief that note-taking is generally more effective when handwritten:

Anna. if you type your notes everything is so - well it is very neat - but at the same time you don't get the memory from - well the muscle memory really - rather than - if you do your exam on the computer you'd have the muscle memory from typing it -

Simon. Now it's revision stage before the exams I'm kind of $-I^{\prime} m$ doing it all on paper rather than rewriting my notes on the computer, because I' $m$ condensing it from there onto paper

It is likely that the shared belief about the importance of handwritten notes is derived from institutional culture as much as from personal experience: a number of students, and one teacher on a different occasion, referred to a research finding which says that knowledge is remembered better if notes are handwritten. The school's move to Microsoft Surface machines and styluses attempted to resolve this tension by enabling digital handwriting, although survey results indicate that this functionality of the Surface had not proved popular, as just 4 out of the 14 in the sample who used a Microsoft Surface reported using the stylus (by contrast, 16 students said they preferred laptops for taking notes in lessons, whilst 26 preferred handwriting).

Many students interviewed described quite elaborate means of running pen and paper study methods in parallel with digital methods, but were nonetheless satisfied with the opportunity to base all their work around their device which (with one exception, Jo) they took to all their lessons. Students perceived some variation in terms of the commitment of their teachers to digital methods:

Mick. there's a little bit of a disparity - some teachers are pro and some are still stuck in pen and paper. It's understandable but sometimes a bit annoying when you're .. and some subjects where it would be better to use a laptop - they're not so keen

Whilst being somewhat reserved on the topic of misusing these devices in school-time, it was widely acknowledged that this was a common issue: "if they're using their laptops they can get completely distracted by Facebook or whatever" (Charlotte). There was a generally agreed feeling that it was their responsibility as sixth formers, and future university students, to learn to manage their own behaviours. They were, though, fairly vague about what constitutes good practice when it came to making judgements about the quality of material they accessed online:

Charlotte. I would use - I don't really know - different websites and then adding them together and if it's - How do you know when you've found something that you think is good or reliable? Um, I don't really know - it's kind of - it just sounds right!

As the survey indicated, the students welcomed clear guidance from their teachers about the websites that are considered best for their studies, and claimed to use less approved sites quite cautiously: 
Jo. You get told what the good sites are.

Caroline. Yeah, you get sent links and things, so - if you are doing particular research for a subject in an essay, my teacher will always send me like websites which have the right information that's reliable, so -... They don't really like you looking at Wikipedia that much, and try and make you look at - the BBC or something ...

There was no question in anyone's mind of wanting to forgo the digital provision in the school, but there were certainly mixed feelings regarding its extent and the expectations surrounding it. In saying that "I just think I would prefer if it was less techy", Jo makes the point that things work best for those that fully embrace the strategy: "I think it's gone too - I think it's kind of better now if you do use your laptop for the lot". Likewise, in the course of the discussion in another focus group, Charlotte came to the conclusion that "I kind of think that it [technology] might be a bit too, like, too used ..". Both students are trying, cautiously, to express their feeling that the school's digital strategy leaves little room for manoeuvre for the less technologically inclined. They were not alone in experiencing this tension in some respects, most evidently in terms of most students having to sustain traditional and digital modes of working in parallel, in the knowledge that they must ultimately privilege the traditional as examinations approach, regardless of the benefits of the digital.

These machines were perceived by their users, and by their teachers, primarily as tools to augment the processes of teaching, learning and managing the various elements of the established curriculum, especially with regard to accumulating and retrieving the knowledge required for critical public examinations. In this respect, it seems that the school's wellresourced approach to making the necessary technologies available had paid dividends, although it is evident that the ambitious aims of encouraging digital working processes had not entirely overcome the inertia of earlier modes of study still prioritised in the assessment system, leading to some degree of compromise and uncertainty amongst the students.

\section{Upper secondary school, Norway.}

Each of the students in the study had 1:1 access to a personal laptop provided by the school, which is the norm in Norwegian upper secondary schools. They could have their computers with them at all times, and they could use them however and whenever they found it relevant. They were expected to take the computers home in order to do homework, and most of the communication between school and students was mediated through a digital learning platform, a learning management system (LMS). Teachers and students could use the LMS to communicate with each other and by sending messages. In the data we draw on in this article, students were expected to use the LMS in all subjects and teachers often referred to resources and assignments there during lessons. All teacher presentations (e.g PowerPoints) and handouts from class were shared there, tests were taken there and assignments were found there. In this sense, all school activities and all written communication between teachers and students were structured through the LMS.

The participating school has a high entrance requirement, thus the students in our data all have grades above the national average. Further, the school emphasizes students' individual freedom, and while they have traditional lessons, parts of the school day are labelled as "work time". In these lessons the students are expected to work individually, and they choose what subjects to engage in. As emphasized by Carlgren et al. (2006), classes with a high degree of individual seatwork such as this one tend to reduce the classroom's 
effectiveness as an oral and communicative space. The amount of time for plenary activities is reduced, and students have considerable individual freedom to decide how to work and with what. This also affects the traditional lessons - in the observed data from this school a large part of the lessons consisted of traditional lectures where teachers took the role of "presenters of information". Teaching sequences using digital support were a frequent activity in the 16 lessons recorded, and in four of those lessons it was the only activity performed by the teacher.

Four focus students were recorded with small head-mounted cameras during 16 lessons in history (4 lessons), Norwegian (8 lessons) and religion and ethics (4 lessons) during a period of three weeks. The head-mounted cameras made it possible to systematically categorize all the texts used by the students. A key finding in this study is that most of the texts students engaged in were digital texts, and they were texts chosen by the students rather than imposed by school (Author 1, 2013). The following figure illustrates how four students (here called Stine, Andreas, Thomas and Hedda) used their laptops during a lesson in history, where the teacher was giving a lecture:
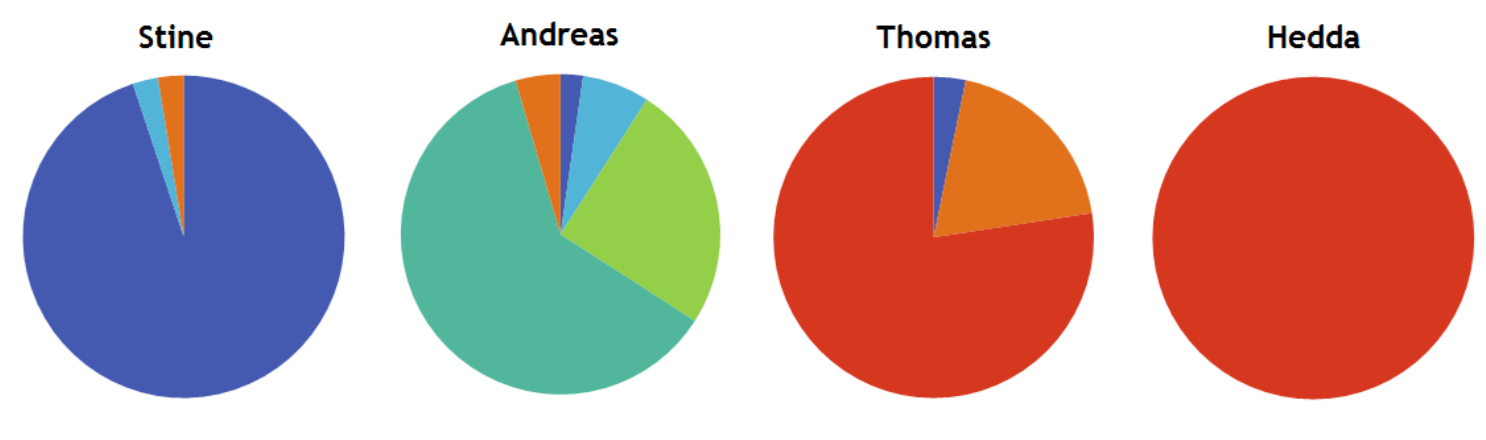

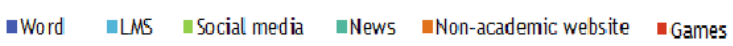

As we can see from Figure 1, the four different students chose to use their Internet access for a variety of different activities. While Stine chose to spend most of her time taking notes in Word, the other students filled most of the lesson with different digital texts such as social media, newspapers and on-line games. One important finding in this study (Author 1 , 2012 ) is that these students did not differentiate between educational use of ICT and other use, as they use their laptops for similar purposes regardless of where they are. Thus, the home/school-distinction made little sense to them, and they dismissed it. As figure 1 suggests, their purposes for using digital technology often revolve around entertainment. In the words of Janet Ward Schofield (2006), the Internet proved to be "an unparalleled temptation to play".

In interview, students were able to elaborate on their use of laptops in educational settings. When asked about how they felt about having access to a computer at all times, and more specifically about what determines their use in school, the four students were consistent in their answers, all expressing that they used their laptops for whatever they wanted, which frequently turned out to be other than taking notes and paying attention. When asked how they knew when they could go online during class, Andreas answered, "When the teacher is teaching," explicitly stating that what he does the most at school, regardless of the subject, is to be on Internet pages that are not related to relevant academic content. As Hedda explained, students navigate their own personal pathways of Internet use in the classroom: 


\begin{abstract}
"it depends entirely on what I feel like doing. ... If we want to take notes we take notes during class, we pay attention, for instance in history and philosophy [optional subject]. I always take notes, because it's so hard, but if we feel like not paying attention during Norwegian we are on VG [newspaper site] or Facebook or whatever (...) I don't know, it's just so natural to log onto Facebook, it's like a habit, in a way. If you go on the Internet you just go to Facebook, kind of, you just check if something has happened" (Hedda)
\end{abstract}

Out of the 16 lessons and the four interviews that were recorded and analysed, it was not possible to identify any targeted and systematic use of technology for the explicit purpose of learning something. It appears that these devices were used in largely personal and individualized ways, with each student's preferences determining their technological repertoire, at school and at home. As summed up in an earlier publication "the students have their own vernacular practices concerning the use of the same technology, which they bring to school and wherever they go. This means that if schools fail to create the need of relevant educational Internet-based practices, the students will continue to use the Internet mainly for their personal vernacular practices, even at school" (Author 1 2012: 92).

\title{
Discussion
}

Our initial exploratory research orientation - how are these devices being used, what purposes are they serving, and in what ways are they proving beneficial? - resulted in findings that are very much in tune with those identified in the discussion of published research above, both in terms of positive and negative aspects.

In terms of how the devices were being used, there was a marked difference between the ways in which they were used with younger and older secondary students. They were used with the 11-12 year old students in the state secondary school with a similar degree of regulation to that reported by Ditzler et al. (2016: 185), and these agreed procedural rules were widely enforced by the teachers. Conversely, the senior secondary students in both the UK independent school and the Norwegian sixth form college were encouraged to take responsibility for their own uses of the machines, and experienced far greater freedom, but also in the case of both schools very much within the constraints of the schools' learning management systems.

The purposes for using the devices in school were exclusively instrumental: above all, the machines are straightforwardly expected to facilitate the ongoing study of the established formal curriculum. This consists of tasks such as: provision of content cheaply and immediately; provision of learning activities (e.g. through proprietary apps, including educational games); ready access to educational material on the Internet (including videos made by teachers for the purpose, within a broad "flipped classroom" model); conveniencetasks such as taking photos of visual activities, providing spellings, note-taking, distribution of notes, looking up information on the Internet, distributing homework tasks, and so on; facilitation of communications between students for collaborative work, and between students and teachers for feedback, guidance and assessment; sharing of student work in the classroom.

The direct benefits for classroom teaching and learning offered by such uses involve convenience, efficiency and some degree of motivational appeal. More speculative, longterm benefits potentially include familiarity with the use of digital technologies of the kind that young people will later encounter in the world of work, including specific workplace practices such as digital collaboration and communication. 
Benefits in terms of teacher workflow, administration and record-keeping were variable. The majority of teachers in the first school held on to their pre-existing means of managing student and timetable information, with only a minority exploring new digital solutions to these tasks. In the second school, though, the move towards Microsoft Onenote represented a major shift towards digital management of a range of tasks, and the universal availability of tablet machines was reported to be crucial in enabling further expansion in this respect. There is no clear evidence of this, either way, from the third school.

Thus a picture emerges of the ways in which personal Internet-connected devices might be expected to fit into the daily activities of schools, as their presence in some form or other becomes normalised. This accords with the wider narrative established in studies referred to above that emphasise the ways in which these devices offer a wealth of practical benefits for facilitating the business of teaching and learning, motivating students and lightening the load on teachers, and operationalising schools' commitment to $21^{\text {st }}$ century skills. As such, this appears to be a generally positive picture, encouraging of further experiments of this kind.

But in other respects such a picture is incomplete, and to some extent misleading. Whilst it was certainly the case that, virtually without exception, the students we spoke to in our studies said they would not wish to be deprived of the machines that they carry with them throughout the school day, some expressed disappointment with how they were used in class, in some cases because that did not amount to much, and in other cases because the effort to use them felt forced. Whilst some students themselves found innovative and practical ways of using the machines in support of their formal learning, it was unquestionably the case that many used them to greater or lesser extents for their own more informal purposes, even when in class.

The teachers we met varied considerably in terms of enthusiasm for implementation projects and the challenge of incorporating this alien element (alien with respect to the ecology and routines of their classroom teaching, at least) into their working lives. Whilst some relished the opportunity to explore new technology-enabled approaches, on occasions along the lines of what Ditzler (quoted above) describes as "transforming learning routines" and "changing teacher roles from delivery of content to facilitator or learning coach", many more questioned the value of committing precious time to the development of fresh expertise. Add to this the concerns of many educators, parents and the media about the distractions and risks posed by giving young people constant access to the Internet in schools, and it appears that the journey towards normalisation might be rather less straightforward and inevitable than previously advertised.

Whilst it is possible to explain these more negative perceptions as by-products of change processes, and possibly only temporary, we argue that they represent a more significant issue: a shortcoming in the narrative that explains and guides the introduction of 1:1 technologies into classrooms. Put simply, this involves the tendency to view these technologies primarily, or even exclusively, as helpful additions to the teaching and learning toolbox, the educational function of which is to service the ongoing delivery of the established curriculum. Useful as such a role for technology may be, it does not allow for or admit of serious attention within education to its own nature and meaning: its operations, advantages and disadvantages for different purposes, the wider digital realm within which it functions, and the challenges it increasingly poses in very many aspects of daily life. 
What might such serious attention involve? At the very least, this would necessitate recognition of the reality of the Internet in young people's lives, now and in the future, and an acceptance of the fact that if schools do not address the topic it is unlikely that anyone else can be counted on to do so. By addressing it, we mean both examination in partnership with young people of what their open access to the Internet and social media mean to them in their lives, and a readiness to teach them vii how to make good use of and good judgements about their participation in the online world, rather than leaving them to learn about these things on their own.

This is important for them as future citizens, but even more so for them as developing individuals. As Packer and Goicoechea (2000) powerfully argue, interaction with others within the context of different communities plays a crucial role in the development of identity:

Human beings are formed and transformed in relationship with others, in the desire for recognition, in the practices of a particular community, and in a manner that will split and initiate a struggle for identity. (2000: 234)

Packer and Goicoechea focus on an ontological perspective of the formation of young people as learners: on how they develop their identities as individuals and learners, at home and at school (2000: 235/6). The role of human relationships in this process is made all the more complex now as young people incorporate the additional context of the online world into their lives, and participate in the social practices they encounter there. Packer and Goicoechea were not referring to the Internet in particular when they wrote, although it is not hard to see relevance here in terms of the communities that many young people connect with, and participate in, online:

A community of practice transforms nature into culture; it posits circumscribed practices for its members, possible ways of being human, possible ways to grasp the world - apprehended first with the body, then with tools and symbols - through participation in social practices and in relationship with other people. (2000: 234)

Jenkins et al. (2005) argued compellingly for formal education to take a lead in helping young people to "grasp the world" by developing the skills to function within the participatory culture of the Internet. Despite calls such as that from Greenhow et al. (2009) for "a stronger focus on students' everyday use of Web 2.0 technologies and their learning with 2.0 both in an outside of the classroom", and the exploration of UK schools' initiatives in that respect from Crook et al. (2008), research does not report progress in that respect since that time. As we have seen, more recent research into 1:1 implementation projects shows considerable interest in exploring how these tools contribute to the realization of schools' existing goals, but reveals little by way of a marked educational focus on the nature and challenges of growing up in the digital era.

\section{Conclusion}

It will be clear by now that we see the outcome of the second and major purpose of this paper - to probe the conceptions of educational value that are implied in the perspectives and assumptions surrounding 1:1 technologies - as revealing a lack of substantive educative engagement with the topic of technology itself. Useful and welcome as the convenience and utility of these technologies are in educational activities within school, we have not come 
across much evidence of their having transformed educational practices for the better, nor of their having enabled innovative approaches to teaching and learning which would not otherwise have been possible, nor - most importantly - do they appear to have been used in order to expand the scope and quality of students' understanding of the world. For a variety of quite understandable reasons, schools prefer to adopt a largely functional relationship to the technologies that they buy (or encourage the parents of their pupils to buy), and do not engage very much with the more contentious or risk-laden aspects of the digital world. This is done, perhaps, in the hope of achieving an acceptable degree of consensus about the justifiability of these investments, in the face of doubts from many quarters concerning their more negative aspects.

Such an approach, in which uses of the technology are largely determined by reference to existing priorities and practices in schools, is inevitably conservative. Most notably in this respect, there is little evidence from published research, or from our own studies, of any extensive educational interest in schools in the digital world, the Internet and social media in particular, as complex and important objects of study in their own right, other than enabling cautious use of the Internet to discover information for learning projects and tasks. Useful as this may often be, it does not come anywhere near addressing what we refer to above as the "vernacular practices" of young people online. This is an area of life generally, and of students' lives in particular, that schools seem to hold at arm's length, beyond fulfilling their important responsibilities with regard to the safeguarding of their students: 1:1 implementations of Internet-connected personal devices have not changed that fact that the Internet itself is largely ignored in schools.

In addition to learning to grapple with the cultural and ethical challenges of life on the Internet, the availability of 1:1 devices also gains greater purpose and meaning when it comes to learning to code, develop skills of computational thinking, and comprehend the pervasive importance of digital data in the world. There are numerous ways in fact that the constant availability of 1:1 devices might achieve value as much for stimulating the serious study of what it means to live and work in the digital era, as for their undoubted utility. The conclusion we draw here is that the convenience benefits of these technologies do not, as things stand, unambiguously constitute a sufficient justification for the cost and disruption involved in their introduction into schools, but that opening the school curriculum to the serious study of the meanings and challenges of the digital world clearly might.

\section{REFERENCES}

The Atlantic 2014. http://www.theatlantic.com/education/archive/2014/08/whats-the-bestdevice-for-interactive-learning/375567/

Author 1 (2012 \& 2013) - details withheld for peer review

BESA (2015) http://www.besa.org.uk/news/besa-press-release-tablet-adoption-continuesrise-barriers-adoption-shift/

Biesta, G. (2012) "Giving Teaching Back to Education: Responding to the Disappearance of the Teacher" in Phenomenology \& Practice, Volume 6 (2012), No. 2, pp. 35-49.

Burden, K. et al. (2012) iPad Scotland Evaluation. Faculty of Education, The University of Hull 
Carlgren, I., Klette, K., Mýrdal, S., Schnack, K., \& Simola, H. (2006). Changes in Nordic teaching practices: From individualized teaching to the teaching of individuals, Scandinavian journal of educational research, 50(3), 301-326

Clark, W. \& Luckin, R. (2012) "What the research says: iPads in the Classroom." London Knowledge Lab

Crook, C. et al. (2008) "Web 2.0 technologies for learning: The current landscape opportunities, challenges and tensions". Becta.

http://dera.ioe.ac.uk/1474/1/becta 2008 web2 currentlandscape litrev.pdf

Ditzler, C., Eunsook Hong, E. \& Strudler, N. (2016) How Tablets Are Utilized in the Classroom, Journal of Research on Technology in Education, 48:3, 181-193, DOI:

10.1080/15391523.2016.1172444

Greenhow, C., Robelia, B. and Hughes, J. E. (2009) "Web 2.0 and Classroom Research: What Path Should We Take Now?" Educational Researcher, Vol. 38, No. 4, pp. 246-259

Heinrich, P. (2012) "The iPad as a Tool for Education - A study of the introduction of iPads at Longfield Academy, Kent". Naace report by 9ine Consulting

Ifenthaler, D. \& Schweinbenz, V. (2016) Students' Acceptance of Tablet PCs in the Classroom, Journal of Research on Technology in Education, 48:4, 306-321, DOI:

10.1080/15391523.2016.1215172

Jahnke, I. \& Kumar, S. (2014) Digital Didactical Designs: Teachers' Integration of iPads for Learning-Centered Processes, Journal of Digital Learning in Teacher Education, 30:3, 81-88, DOI: 10.1080/21532974.2014.891876

Jenkins, H., with Ravi Purushotma, Margaret Weigel, Katie Clinton, and Alice J. Robinson (2008) Confronting the Challenges of Participatory Culture, Media Education for the 21st Century. Cambridge, MA: The MIT Press

Mango, O. (2015) “iPAD USE AND STUDENT ENGAGEMENT IN THE CLASSROOM" TOJET: The Turkish Online Journal of Educational Technology - January 2015, volume 14 issue 1

Katherine McKnight, Kimberly O'Malley, Roxanne Ruzic, Maria Kelly Horsley, John J. Franey \& Katherine Bassett (2016) Teaching in a Digital Age: How Educators Use Technology to Improve Student Learning, Journal of Research on Technology in Education, 48:3, 194-211, DOI: 10.1080/15391523.2016.1175856

Packer, M.J. and Goicoechea, J. (2000) "Sociolcultural and Constructivist Theories of Learning: Ontology, Not Just Epistemology". Educational Psychologist, 35(4), 227-241

Peluso, D. (2012) "The fast-paced iPad revolution: Can educators stay up to date and relevant about these ubiquitous devices?" British Journal of Educational Technology Vol 43 No 4 2012 E125-E127 doi:10.1111/j.1467-8535.2012.01310.x 
Selwyn, N. (2014) "Making the most of the 'micro': revisiting the social shaping of microcomputing in UK schools", Oxford Review of Education, 40:2, 170-188

Warschauer, Marl and Ames, Morgan (2010) “Can One Laptop per Child Save the World's Poor?" Journal of International Affairs. Vol. 64, No. 1, Innovating for Development (Fall/Winter 2010) pp. 35-51

Willcocks, B. and Redmond, P. (2014) "Evaluating a 1-to-1 iPad Project: Beyond Rose Coloured Glasses". Australian Computers in Education Conference 2014. https://eprints.usq.edu.au/26253/8/Willocks_Redmond_ACEC_2014_PV.pdf

\footnotetext{
${ }^{i}$ http://www.edweek.org/ew/articles/2006/10/18/08cuban.h26.html

ii https://www.youtube.com/watch?v=6inRum2FTrg

iii http://en.unesco.org/youthmobile

iv http://www.huffingtonpost.com/jane-margolis/the-ipadsinschools-challe b 4032363.html

${ }^{v}$ https://www.gov.uk/government/publications/national-curriculum-in-england-computing-programmes-ofstudy/national-curriculum-in-england-computing-programmes-of-study

vi https://blogs.msdn.microsoft.com/ukschools/page/2/

vii “... rather than to think of the school as a place for learning we should think of it as a place for teaching. One can, after all, learn anywhere, but the gift of teaching is only 'available' in a very small number of places and the school is definitely one of them." (Biesta 2012: 41)
} 